\title{
Avaliação do Efeito de um Óleo Parafínico sobre o Comportamento Físico-Químico de Tubulações de Polietileno de Alta Densidade
}

\author{
Amélia A. U. Torres, José Roberto M. d’Almeida \\ Departamento de Engenharia de Materiais, Pontifícia Universidade Católica do Rio de Janeiro
}

\author{
Jean-Pierre Habas \\ Institut Pluridisciplinaire de Recherche sur l'Environnement et les Matériaux, Université de Pau et des Pays de l'Adour
}

\begin{abstract}
Resumo: Nesse trabalho são investigados os efeitos causados por um óleo parafínico sobre o comportamento físico-químico de dutos de polietileno de alta densidade (PEAD). Os efeitos causados nos dutos de PEAD foram avaliados em função do tempo e da temperatura de exposição através de análises gravimétrica e termogravimétrica e por espectroscopia no infravermelho. Os dados gravimétricos puderam ser satisfatoriamente descritos pela Lei de Fick. Os resultados de FTIR indicaram que não ocorreram modificações estruturais importantes no PEAD exposto a esse óleo e que o processo de envelhecimento do PEAD foi do tipo físico, já que nenhuma alteração na estrutura química do polímero foi detectada.
\end{abstract}

Palavras-chave: PEAD, dutos, derivados de petróleo, envelhecimento, difusão, termogravimetria, FTIR.

\section{Evaluation of the effect caused by a paraphinic oil on the physicochemical behavior of high-density polyethylene pipes}

\begin{abstract}
The effects caused by a paraphinic oil on the physicochemical behavior of high-density polyehtylene pipes were investigated, as a function of time and temperature. These effects were evaluated by thermogravimetric and gravimetric analysis and by FTIR. The gravimetric data were satisfactorily described using the Fick's law, and the FTIR results showed that no main structural modifications have occurred after exposure of the HDPE pipes to this oil. From the results obtained it was concluded that physical aging was occurring, since the chemical structure of the polymer was not altered.
\end{abstract}

Keywords: HDPE, pipes, oil derivatives, aging, diffusion, thermogravimetry, FTIR.

\section{Introdução}

Tubulações de aço-carbono são amplamente usadas para o transporte de derivados de petróleo em muitas redes de distribuição. Estas tubulações apresentam, entretanto, duas desvantagens importantes, a saber: corrosão e perda da pressão devido à rugosidade interna elevada ${ }^{[1]}$. Assim sendo, diversas distribuidoras de derivados de petróleo têm substituído as tubulações metálicas por dutos poliméricos. Entre esses, destacam-se os dutos de polietileno de alta densidade (PEAD), que representam uma boa alternativa tanto do ponto de vista técnico quanto econômico. Entretanto, o emprego desses dutos também apresenta alguns problemas, tais como inchamento e micro-fissuras ${ }^{[2]}$, especialmente nas linhas de distribuição de álcool, óleo e outros combustíveis.

Os efeitos anteriormente citados ocorrem devido ao envelhecimento do polímero, decorrente de um processo físico e/ou químico produzido pela interação do polímero com o ambiente ao qual está exposto (temperatura, umidade, poluentes líquidos ou gasosos e fontes de radiação, entre outros). Ao nível molecular esse fenômeno pode modificar a estrutura química do material e/ou sua composição. Estas mesmas mudanças podem implicar, ao nível macroscópico, diferentes efeitos como a alteração dimensional do produto ou a variação de suas propriedades mecânicas, elétricas, químicas ou térmicas ${ }^{[2,3]}$. Assim, o envelhecimento dos polímeros pode ser sinônimo de degradação. Por isso esse tema é bastante importante no âmbito de uma aplicação industrial, porque a mudança das características físicas e/ou químicas diminui o tempo de vida útil de uma peça polimérica em serviço ${ }^{[4-6]}$. Além disso, conhecer os diferentes mecanismos que atuam em um determinado material polimérico é indispensável para prevenir, controlar ou prognosticar o modo e o momento de sua falha.

Os diferentes fenômenos de envelhecimento nos materiais poliméricos podem ser classificados em dois tipos ${ }^{[7]}$. $\mathrm{O}$ primeiro define os processos que afetam a estrutura química do polímero, e por tal razão é denominado envelhecimento químico. O segundo compreende mecanismos de envelhecimento que induzem mudanças nas propriedades do polímero sem alterar a integridade das cadeias poliméricas. Por isso são qualificados de físicos.

$\mathrm{O}$ envelhecimento químico inclui fenômenos variados que apresentam um ponto comum: induzem a quebra de cadeias moleculares e a formação de macro-radicais. A oxidação, por exemplo, corresponde ao ataque e a reação do oxigênio presente na atmosfera ou em um líquido e que induz a produção de unidades secundárias chamadas peróxidos ou hidroperóxidos. A degradação térmica de um polímero também é um exemplo de envelhecimento químico. De fato, se a energia térmica imposta ao polímero for superior a energia das ligações químicas, essas ligações podem se romper e levar, pouco a pouco, a uma redução da massa molar das cadeias poliméricas. Da mesma forma a radiação UV pode causar a quebra da cadeia macromolecular ${ }^{[8-10]}$.

A associação dos diferentes mecanismos descritos acima é comum. Por exemplo, é bem sabido que os polímeros são susceptíveis à degradação devido ao intemperismo, onde há uma associação da oxidação pela ação do oxigênio atmosférico com uma fotodegradação envolvendo fótons de luz ultravioleta solar. Além disso, estas reações podem ser aceleradas por temperaturas 
elevadas causadas pela exposição ao Sol, bem como, também, pela presença de tensões mecânicas (aplicadas externamente ou tensões residuais do processo de conformação) $)^{[11-13]}$.

A difusão de um líquido em uma matriz polimérica causa, preferencialmente, um envelhecimento físico. As moléculas do líquido se difundem no volume livre existente entre as cadeias poliméricas, conforme mostrado esquematicamente na Figura 1. Assim, a difusão do solvente no polímero pode ocorrer sem causar qualquer reação química. Porém, irá depender da morfologia do polímero, diminuindo com o grau de cristalinidade (caso dos polímeros termoplásticos semicristalinos) ou com o grau de reticulação (caso das borrachas e dos polímeros termofixos). Além disso, a polaridade da cadeia polimérica também é um fator que afeta a difusividade de um solvente em um polímero. Como a polaridade de um polímero está relacionada com a assimetria da estrutura molecular, um polímero polar tem uma estrutura mais assimétrica do que um polímero apolar. Assim, o polímero polar tem um volume livre maior do que o polímero apolar e, portanto, os polímeros polares são mais sensíveis ao fenômeno de difusão de um líquido que os polímeros apolares ${ }^{[14]}$.

A interação líquido-polímero é bem descrita pela equação de Flory-Huggins $^{[15]}$ (Equação 1):

$$
\chi_{s p}=\frac{V}{R T}\left(\delta_{S}-\delta_{P}\right)^{2}+\chi_{s}
$$

onde $\chi_{s p}$ é o coeficiente de interação que traduz a afinidade do polímero (P) com o solvente (S), V é o volume molar do líquido, $R$ é a constante dos gases perfeitos, $T$ é a temperatura $(\mathrm{K}), \delta_{s} \mathrm{e}$ $\delta_{p}$ são os parâmetros de solubilidade do líquido e do polímero, respectivamente, e $\chi_{s}$ é um coeficiente de entropia ( $\left.\cong 0,34\right)$. Quanto menor é o valor de $\chi_{s p}$, maior será a afinidade entre o polímero e o líquido. Assim, o fenômeno de difusão, e por consequência o envelhecimento do polímero, pode ser favorecido por dois aspectos: seja por uma pequena diferença entre $\delta_{s}$ e $\delta_{p}$ ou por um aumento da temperatura.

Nesse trabalho é feito um estudo do efeito de um óleo de base parafínica sobre o comportamento físico-químico do PEAD, em função do tempo e da temperatura de exposição. Os efeitos do envelhecimento foram avaliados usando-se técnicas gravimétricas e termogravimétricas, bem como espectroscopia no infravermelho.

\section{Materiais e Métodos}

Um tubo de PEAD comercial, usado no transporte de derivados de petróleo, foi usado nesse trabalho. Tendo em vista que nos diversos derivados de petróleo podem existir vários componentes químicos muito diferentes, sendo que alguns são parafínicos e outros são aromáticos ${ }^{[16,17]}$, nesse trabalho o envelhecimento do PEAD foi avaliado empregando-se um fluido parafínico de modo a estudar o comportamento do PEAD em contato exclusivamente com as unidades parafínicas.
De acordo com o fabricante (Esso Company, EUA), o produto usado é formulado a base de óleos parafínicos, derivados do petróleo, com um alto grau de refino ${ }^{[18]}$. As parafinas são grupos químicos lineares constituídos exclusivamente por grupos metilenos $\left(\mathrm{CH}_{2}\right)$. Essa estrutura química é similar a do polietileno, porém as parafinas apresentam menor massa molar.

O PEAD e o fluido modelo foram inicialmente caracterizados por espectroscopia no infra-vermelho com transformada de Fourrier, FT-IR, e por análise termogravimétrica, TGA. Nesse trabalho, as análises de FT-IR foram realizadas no equipamento Spectrum One, Perkin-Elmer, utilizando o acessório de refletância total atenuada (ATR), com um cristal misto "diamante/ZnSe"; de modo que foi possível a caracterização direta das amostras, sem nenhuma preparação preliminar. Para o PEAD foram feitas análises tanto da superfície externa, quanto da superfície interna do tubo, de modo a verificar se o processo de fabricação do tubo não acarreta algum tipo de heterogeneidade na estrutura do polietileno. As análises termogravimétricas foram realizadas no equipamento TGA Q50, da TA Instruments, sob atmosfera inerte $\left(\mathrm{N}_{2}\right)$, no intervalo de temperatura compreendido entre 20 e $550{ }^{\circ} \mathrm{C}$, com uma velocidade de aquecimento de $10{ }^{\circ} \mathrm{C} / \mathrm{min}$.

A seguir, corpos de prova com $80 \mathrm{~mm}$ de comprimento, $10 \mathrm{~mm}$ de largura e $2 \mathrm{~mm}$ de espessura foram imersos no fluido em recipientes hermeticamente fechados e à pressão atmosférica. Esses recipientes foram colocados em estufas, em duas temperaturas diferentes $\left(20\right.$ e $\left.50{ }^{\circ} \mathrm{C}\right)$, para se avaliar o efeito da temperatura sobre o processo de envelhecimento. Essas análises de envelhecimento foram realizadas até um tempo de 150 dias, para os ensaios gravimétricos, e de aproximadamente 3 meses (84 dias) para as demais caracterizações.

O processo de absorção do fluido pelo PEAD foi avaliado seguindo-se as recomendações da norma ASTM D-570 ${ }^{[19]}$. As amostras em imersão foram pesadas em intervalos regulares de tempo em uma balança analítica com precisão de $\pm 0,0001$ g. Para obter dados gravimétricos confiáveis, a seguinte metodologia foi adotada para cada medida: i) os corpos de prova foram retirados do fluído após de um determinado tempo de envelhecimento e foram secos com papel absorvente; ii) as amostras foram, então, deixadas ao ar livre por 20 minutos. Este tempo de exposição ao ar foi determinado experimentalmente, como sendo o tempo necessário para que houvesse a volatilização total do solvente da superfície das amostras, restando apenas o solvente que havia se difundido para o interior das mesmas. Esse tempo experimental foi determinado como sendo o tempo no qual ocorreu a estabilização da perda de massa das amostras após a sua retirada dos recipientes de imersão ${ }^{[20]}$; e iii) foi feita, a seguir, a pesagem das amostras. Os resultados obtidos foram expressos em termos da variação relativa de massa, dada pela Equação 2:

$$
M_{s}(\%)=\frac{M_{t}-M_{o}}{M_{o}} \times 100
$$
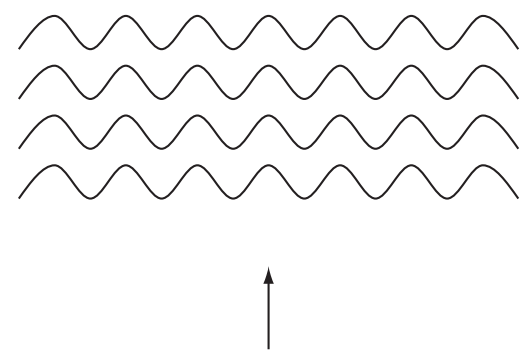

Cadeias poliméricas

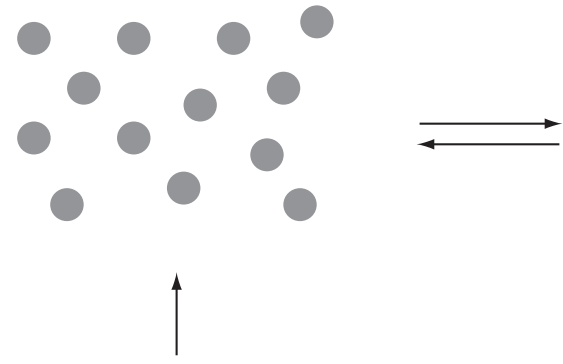

Líquido

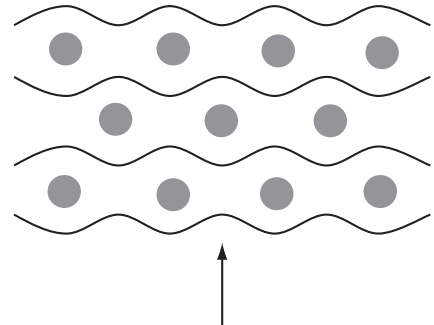

Polímero plastificado

Figura 1. Representação esquemática da difusão de um líquido em um polímero (envelhecimento físico). 
onde $M_{t}$ é a massa do polímero com o solvente em um tempo $t$ e $M_{o}$ é a massa inicial do corpo de prova.

Após o tempo de envelhecimento de 84 dias, os corpos de prova envelhecidos foram analisados por FT-IR e TGA, usando-se os mesmos procedimentos experimentais descritos anteriormente.

\section{Resultados Experimentais}

A Figura 2 mostra o espectro de FT-IR da parede interna do tubo de PEAD. Foi dado maior destaque a essa região em relação a parede externa, pois ela é que estará em contato com os diversos derivados de petróleo. No caso do PEAD, formado pela repetição do grupo - $\left(\mathrm{CH}_{2}\right)$-, deve-se observar as bandas de absorbância características das ligações simples $\mathrm{C}-\mathrm{H}$ do tipo $\mathrm{sp}^{3}$ e das ligações covalentes $\mathrm{C}-\mathrm{C}$. De fato, o espectro mostra as três bandas de absorção associadas aos três modos de vibração da ligação $\mathrm{C}$-H, cujos valores dos números de onda se situam nas seguintes regiões espectrais ${ }^{[21]}$ : valência ou "stretching" entre 2950 e $2850 \mathrm{~cm}^{-1}$; pêndulo ou "bending" entre 1350 e $1450 \mathrm{~cm}^{-1}$; torção ou "rocking" aproximadamente em $700 \mathrm{~cm}^{-1}$.

A Figura 3 indica que, na verdade, cada banda é formada por dois picos. Este fenômeno é devido ao fato de que a frequência de vibração de uma ligação depende do meio que a envolve. Assim, para o polietileno, cada pico corresponde a uma configuração C-H particular, como mostrado na Figura 4. Uma banda é típica das ligações dentro da cadeia polimérica (2), enquanto a outra corresponde à ligação $\mathrm{C}-\mathrm{H}$ nas extremidades da cadeia polimérica (1) ${ }^{[22]}$. A amplitude relativa de um pico sobre o outro depende da importância relativa de cada tipo de ligação e de seu grau de vibração.

O PEAD também apresenta as ligações C-C que são normalmente observadas com pico(s) de absorbância em um número de onda na região entre $1000-1250 \mathrm{~cm}^{-1[22]}$. Porém, analisando o espectro do PEAD mostrado na Figura 2, observa-se que não há presença dessas vibrações. Isso decorre tanto da simetria da cadeia polimérica do polietileno, que induz à simetria das vibrações $\mathrm{C}-\mathrm{H}$, quanto à pequena massa dos grupos laterais que não pode produzir por inércia o movimento do carbono. Assim sendo, a ligação C-C será observada apenas em polímeros que apresentam uma assimetria da cadeia, como no caso do polipropileno e do poliestireno, ou que tenham uma estrutura simétrica, mas com grupos pesados, como no caso do PTFE ${ }^{[22,23]}$.

Pode-se observar ainda no espectro do PEAD, Figura 2, a presença de duas regiões largas de absorbância. O primeiro domínio espectral entre $3200-3400 \mathrm{~cm}^{-1}$ é característico dos grupos $\mathrm{OH}$ (hidroxilas) e destaca a presença de umidade no tubo ${ }^{[24,25]}$. O segundo domínio espectral presente entre $1550-1700 \mathrm{~cm}^{-1}$, revela a existência de unidades carbonila $(\mathrm{C}=\mathrm{O})$. Esses grupos químicos ocorrem, provavelmente, por uma ligeira oxidação produzida pelo processo de extrusão do duto ${ }^{[26]}$.

A comparação dos espectros de FTIR referentes a parte interna e a parte externa do tubo está mostrada na Figura 5. Pode-se observar as mesmas características básicas entre os dois espectros, incluindo as bandas de absorbância relativas a umidade e a oxidação superficial. Entretanto, outros picos também podem ser observados. Duas hipóteses podem ser propostas para interpretar a origem dessas últimas bandas de absorbância. A primeira possibilidade consiste em atribuir esses picos a aditivos utilizados para melhorar o fluxo do polímero fundido dentro da ferramenta da extrusora utilizada para a fabricação do duto. Os aditivos são formados de moléculas pequenas, apresentando uma baixa viscosidade e, portanto, podem migrar para a superfície do duto onde atuam como lubrificantes; a segunda possibilidade é a presença de outro componente químico colocado na superfície do duto para permitir a deposição de tintas. Embora essa questão permaneça em aberto, pode-se verificar, entretanto, pela Figura 5 que o material usado é homogêneo.

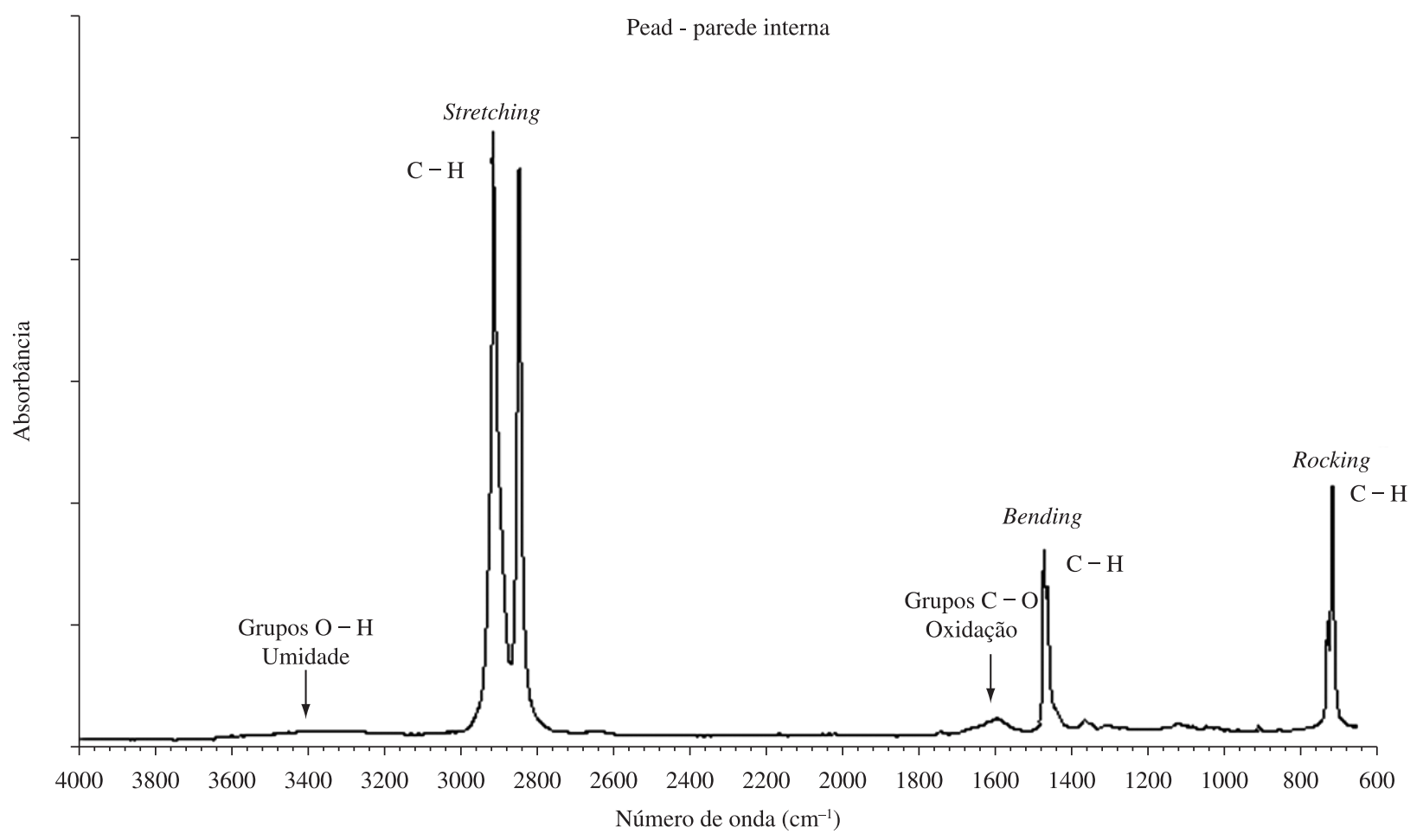

Figura 2. Espectro infravermelho do PEAD. Parede interna do tubo. 


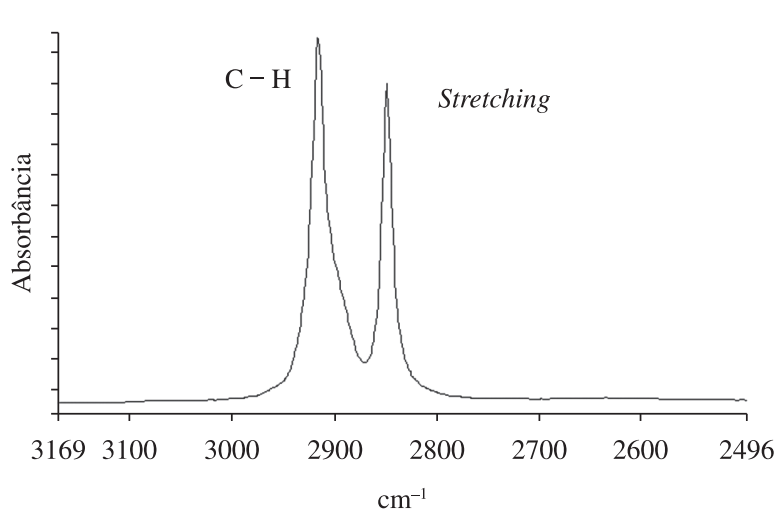

(a)

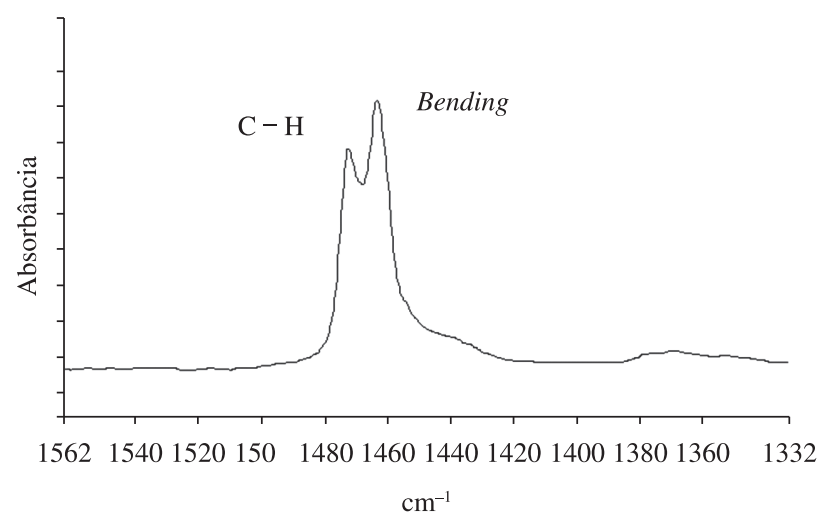

(b)

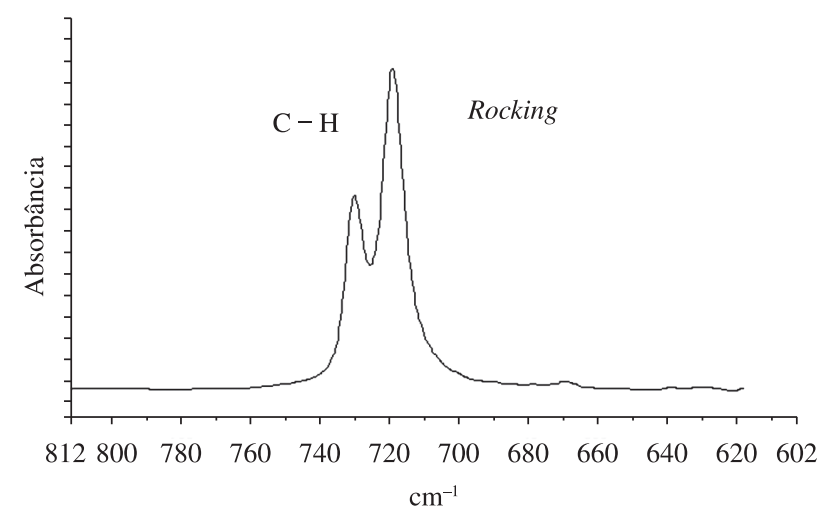

(c)

Figura 3. Detalhe das bandas de vibração das ligações C-H. a) Região entre $2500-3200 \mathrm{~cm}^{-1}$; b) região entre $1300-1550 \mathrm{~cm}^{-1}$; e c) região entre $600-800$ cm-1.

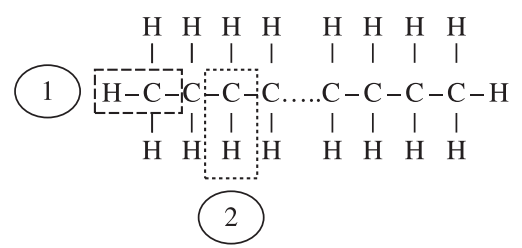

Figura 4. Representação esquemática das ligações C-H com diferentes vibrações.

A Figura 6 mostra o espectro do fluido parafínico. Conforme descrito anteriormente, a estrutura química desse fluido é semelhante à do polietileno. Assim sendo, o espectro apresenta bandas de absorção características dos três modos de vibrações da ligação $\mathrm{C}-\mathrm{H}$, como descrito para o PEAD. Essa constatação é importante, pois devido a semelhança das estruturas químicas pode-se postular que as moléculas pequenas desse fluido devem se difundir facilmente no polímero.

Os resultados da análise termogravimétrica do material não envelhecido e do fluido estão mostrados na Figura 7. Para o PEAD, Figura 7a, estão identificadas as temperaturas de início da variação de massa (queda de $\sim 1 \%$ ), $T_{i}=300{ }^{\circ} \mathrm{C}$ e a temperatura onde o processo responsável pela variação de massa foi concluído, $T_{f}=490^{\circ} \mathrm{C}$. Pode-se observar que entre essas temperaturas, a degradação do PEAD foi quase completa, com uma perda de massa de $99 \%$. Além disso, foi determinada a temperatura na qual o fenômeno de degradação do polímero é acelerado, obtida com a tangente da inclinação da curva (onset point), $T_{o}=440{ }^{\circ} \mathrm{C}$. Determinou-se ainda a temperatura onde a velocidade de decomposição é máxima, $T=460^{\circ} \mathrm{C}$, que corresponde ao máximo do pico da curva da derivada, DTG. Toda esta região corresponde à ruptura termolítica das cadeias macromoleculares do polímero. As unidades químicas produzidas são voláteis nessa faixa de temperatura e induzem a perda irreversível de peso. De um ponto de vista prático, esta análise nos dá a faixa da temperatura à qual o polímero não pode ser exposto.

$\mathrm{Na}$ curva da Figura 7b, relativa ao óleo parafínico, pode-se observar que entre a temperatura ambiente e $100{ }^{\circ} \mathrm{C}$, há uma perda de massa de aproximadamente $1 \%$. A partir desta última temperatura, a inclinação da curva indica o início da evaporação do fluido. O fenômeno é acelerado para $T>188^{\circ} \mathrm{C}$. Por outro lado, a curva da derivada da massa (DTG) apresenta um pico, cujo máximo se encontra a uma temperatura de $250{ }^{\circ} \mathrm{C}$, que indica a máxima velocidade de evaporação. Para $T>275{ }^{\circ} \mathrm{C}$, a volatilização do composto é quase completa.

A análise comparativa dos diferentes resultados de TGA mostra, como previsto, que o fluido evapora a uma temperatura inferior à temperatura de degradação do PEAD.

Os resultados da absorção do fluido no PEAD, em função do tempo de imersão e da temperatura, estão mostrados na Figura 8. Pode-se observar que a difusão do óleo no PEAD foi elevada, o que concorda com a análise por FT-IR que mostra semelhança das estruturas químicas. A $50{ }^{\circ} \mathrm{C}$, o aumento relativo de massa devido à absorção acontece nos primeiros 35 dias de envelhecimento, e alcança o limite máximo em 44 dias $(\sim 6 \%)$. Esse ponto crítico corresponde ao princípio do fenômeno de "saturação". Ou seja, a quantidade máxima de fluido que o PEAD pode absorver e que está relacionada ao volume livre presente entre as cadeias do polímero. O fenômeno de saturação é também qualificado de "equilíbrio", porque o líquido absorvido não fica estático, pois se estabelece uma 


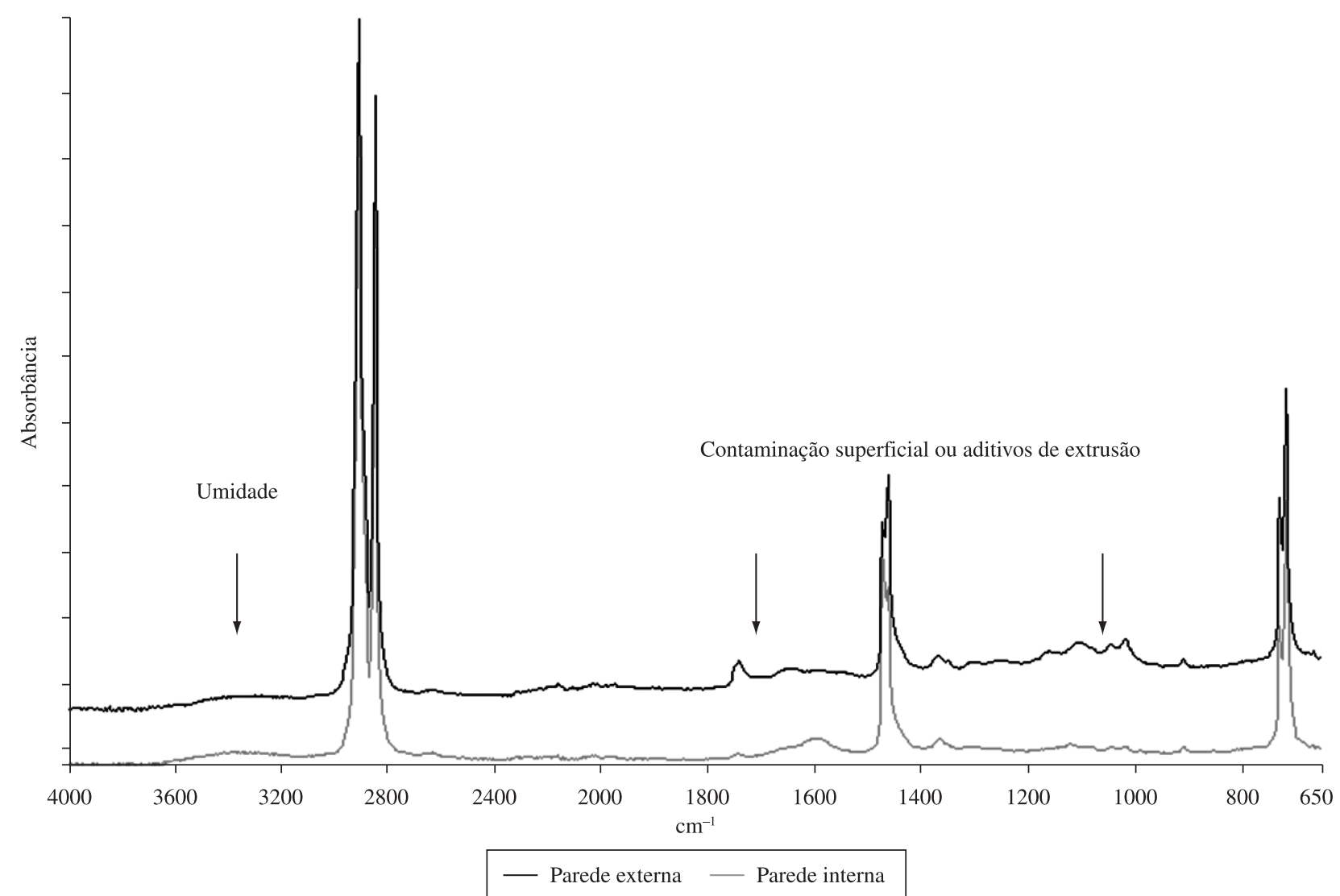

Figura 5. Espectro comparativo entre a parede interna e externa dos dutos de PEAD.

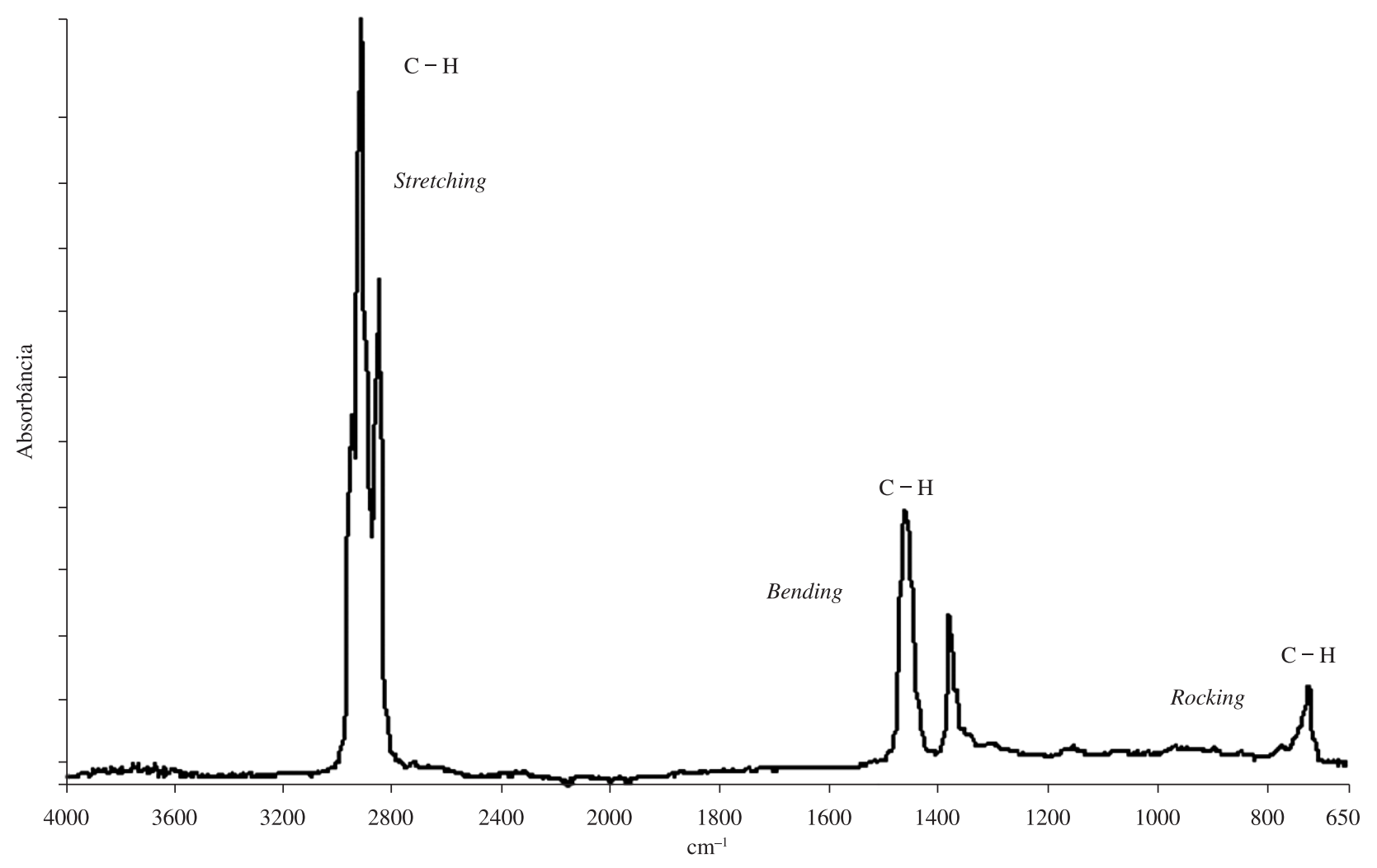

Figura 6. Espectro infravermelho do fluido parafínico. 

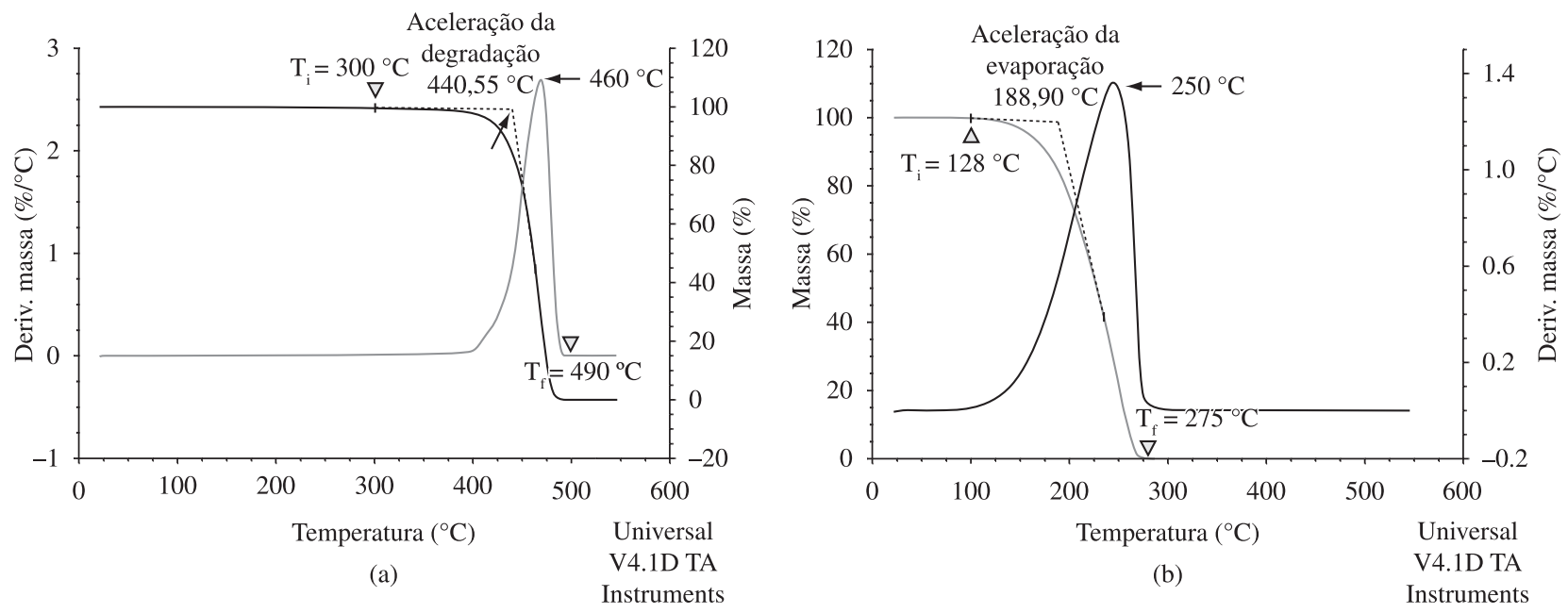

- Massa - Derivada

Figura 7. Curvas termogravimétricas para o: a) PEAD e b) fluido parafínico.

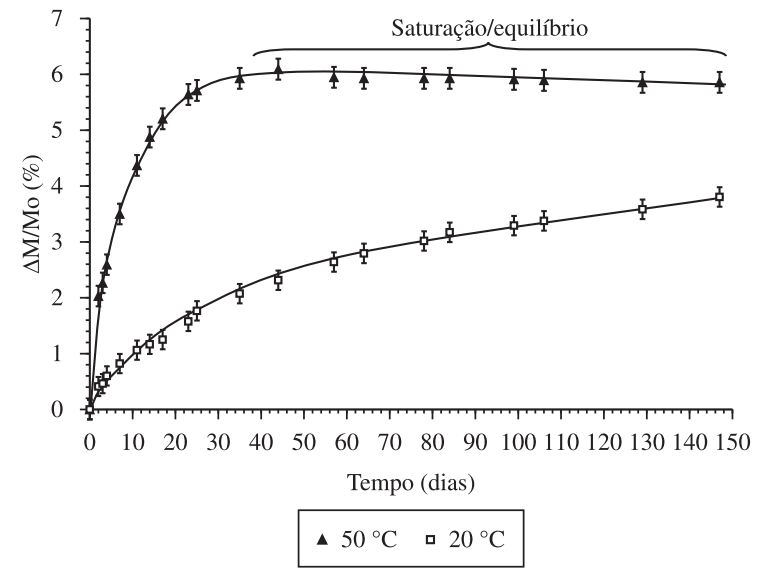

Figura 8. Curvas de absorção do óleo em função da temperatura.

troca contínua com o líquido do recipiente que envolve o PEAD. A $20{ }^{\circ} \mathrm{C}$, o valor da massa aumenta mais lentamente com o tempo de imersão e o ponto de equilíbrio é mais difícil de ser determinado mesmo após 150 dias de envelhecimento. No entanto, esse valor pode ser estimado usando a equação de Fick como sendo próximo a $4 \%$.

A diferença de comportamento em relação à temperatura é devida a diferentes fatores. Primeiramente, o volume livre maior do PEAD a $50{ }^{\circ} \mathrm{C}$, devido à dilatação da amostra, participa da aceleração do fenômeno de difusão. Este aspecto está previsto na lei de Fick, que supõe uma ativação térmica do fenômeno de difusão ${ }^{[27]}$. Além disso, a viscosidade do fluido diminui com o aumento de temperatura, o que também facilita a difusão desse no polímero.

Os dados experimentais das curvas de absorção foram analisados usando-se o modelo de difusão de Fick. Observou-se, em particular, para a parte inicial das curvas que o ganho de peso do corpo de prova é proporcional à raiz quadrada do tempo de envelhecimento. Assim sendo, pode-se afirmar que a absorção desse fluido pelo PEAD é um processo controlado por difusão ${ }^{[27]}$. Nessa região, o coeficiente de difusão $D$ é definido por:

$$
D=\frac{\pi}{4} \frac{L^{2}}{t}\left(\frac{M_{t}}{M_{\infty}}\right)^{2}
$$

onde $M_{\infty}$ é o ganho de peso máximo e $L$ é a espessura do corpo de prova. A Equação 3 é equivalente a:

$$
\left(\frac{M_{t}}{M_{\infty}}\right)=\sqrt{t} \times \frac{2}{L} \sqrt{\frac{D}{\pi}}
$$

Logo, o coeficiente de difusão pode ser avaliado traçando-se as variações de $M / M_{\infty} v s . \sqrt{t}$ pela determinação da inclinação da reta, $P$, ou seja:

$$
D=\frac{\pi \times(P \times L)^{2}}{4}
$$

Os valores do coeficiente de difusão obtidos foram de $0,207 \times 10^{-12}$ e $1,54 \times 10^{-12} \mathrm{~m}^{2} \cdot \mathrm{s}^{-1}$ para, respectivamente, as temperaturas de 20 e $50{ }^{\circ} \mathrm{C}$.

Em função dos resultados obtidos pelas análises de FT-IR era, de fato, esperado um valor elevado de absorção do fluido no PEAD, visto que ambos apresentam semelhanças importantes nas suas estruturas químicas.

A Figura 9 apresenta as curvas termogravimétricas do PEAD envelhecido durante 84 dias a 20 e $50{ }^{\circ} \mathrm{C}$. Nessa figura estão mostradas também, como referência, as curvas para o PEAD antes do envelhecimento e para o fluido. Para ambas as temperaturas a curva mostra uma perda de massa que começa na temperatura de início de evaporação do fluido. Os resultados mostram, também, claramente o efeito da ativação térmica do fenômeno de difusão, com o teor de solvente eliminado sendo maior na temperatura mais elevada $\left(7,1 \%\right.$ a $50{ }^{\circ} \mathrm{C}$ contra $4,7 \%$ a $\left.20{ }^{\circ} \mathrm{C}\right)$. Observa-se ainda que, mesmo para o tempo de imersão mais longo não foi possível detectar qualquer deslocamento da temperatura de degradação do PEAD. Assim, pode-se afirmar que o fluido parafínico não foi capaz de solubilizar o polietileno. Esse resultado tem boa concordância com os dados de gravimetria, Figura 8, onde não há queda de peso após um determinado tempo de imersão. Além disso, os espectros de FT-IR obtidos não mostraram nenhum novo pico de absorbância. Isso indica que o fluido, de fato, não causou qualquer alteração química das cadeias do PEAD. Esses resultados de FT-IR sugerem o fato de que o envelhecimento do PEAD em contato com o fluido parafínico foi puramente do tipo físico. Ou seja, o fluido se difunde facilmente no polímero mas não há necessariamente alteração no espectro do PEAD. 


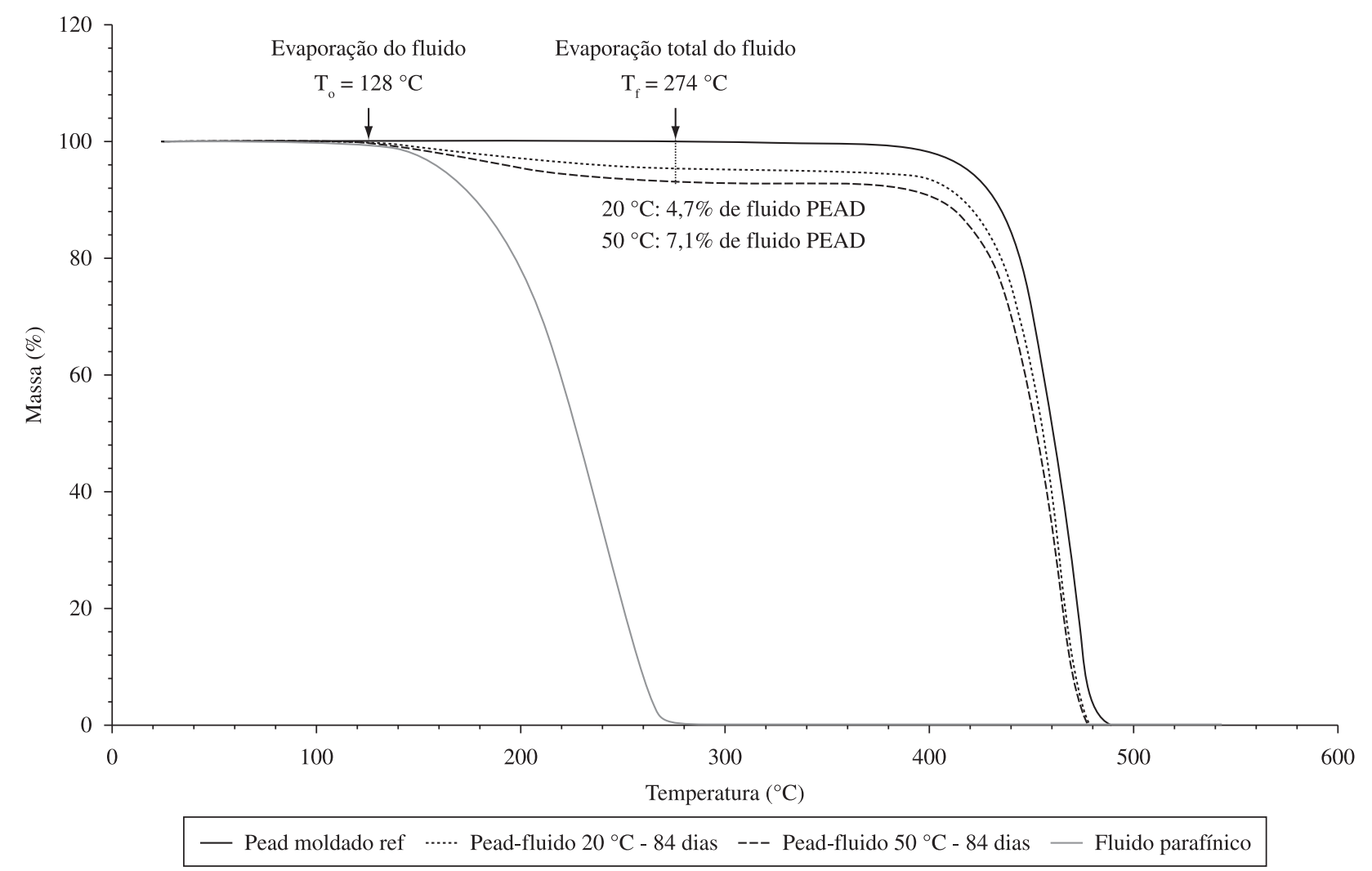

Figura 9. Análise termogravimétrica do PEAD envelhecido a 20 e $50{ }^{\circ} \mathrm{C}(84$ dias de imersão).

\section{Conclusões}

Os resultados das análises gravimétricas e termogravimétricas mostraram que vários fatores influenciam o comportamento do PEAD frente ao fluido parafínico, derivado de petróleo. Em particular, a afinidade fluido-polímero é muito dependente da temperatura. Contudo, os ensaios realizados indicaram que a estrutura do polímero não sofre mudança, ainda que exposto a períodos longos de envelhecimento. Isso foi claramente evidenciado através dos ensaios de FT-IR, pois nenhum novo pico de absorbância foi observado nos espectros. Assim, de acordo com os resultados obtidos dos ensaios realizados, pode-se concluir que a difusão do fluido parafínico no duto de PEAD resulta em um processo de envelhecimento puramente do tipo físico. Esse processo induz a plastificação das cadeias do polímero, a partir da absorção pelas paredes do tubo de até $7,1 \%$ de óleo a $50{ }^{\circ} \mathrm{C}$ e de $4,7 \%$ a $20{ }^{\circ} \mathrm{C}$, e assim poderá induzir a deformação progressiva do duto. Vale ressaltar que os ensaios foram realizados à pressão atmosférica e que os dutos trabalham sob pressão, o que pode aumentar ainda mais a difusividade do óleo no polímero.

\section{Agradecimentos}

Ao $\mathrm{CNPq}$ pelo apoio financeiro.

\section{Referências Bibliográficas}

1. Choi, Y.-S.; Chung M.-K. \& Kim, J.-G. - Mater. Sci. Eng., 47, p.384 (2004).

2. Schouwenaars, R.; Jacobo, V. H.; Ramos, E. \& Ortiz, A. - Eng. Fail. Anal., 14, p.1124 (2007).

3. Verdu, J. - J. Macromol. Sci. Pure Appl. Chem., A31, p.1383 (1994).
4. Darlington, M. W.; McConkey, B. H. \& Saunders, D. W. - J. Mater. Sci., 6, 1447 (1971).

5. Attwood, J.; Philip, M.; Hulme, A.; Williams, G. \& Shipton, P. - Polym. Degrad. Stab., 91, p.3407 (2006).

6. Gulmine, J. V. \& Akcelrud, L. - Polym. Test., 25, p.932 (2006).

7. Zaikov, G. E.; Bouchachenko, A. L. \& Ivanov, V. B. - "Aging of polymers, polymer blends and polymer composites", vol.2, Nova Publishers, New York (2002).

8. Gijsman, P.; Meijers, G. \& Vitarelli, G. - Polym. Degrad. Stab., 65, p.433 (1999).

9. Gijsman, P.; Hennekens, J. \& Janssen K. - Polym. Degrad. Stab., 46, p.63 (1994).

10. Navarro, R. F.; d'Almeida, J. R. M. \& Rabello, M. S. - J. Mater. Sci., 42, p.2167 (2007).

11. Bajer, K.; Kaczmarek, H; Dzwonkowski, J.; Stasiek, A. \& Oldak, D. J. Appl. Polym. Sci., 103, p.2197 (2007).

12. Teare, D. O. H.; Ton-That, C. \& Bradley, R. H. - Surf. Inter. Anal., 29, p.276 (2000).

13. Dear, J. P. \& Mason, N. S. - Proc. IME J. Mater. Des. Appl., 220, p.97 (2006).

14. Struik, L. C. E. - Polymer, 30, p.815 (1989).

15. McKenna, G. B.; Flynn, K. M. - Poly. Commun., 29, p.272, 1988.

16. Kaufmann, T. G.; Kaldor, A.; Stuntz, G. F.; Kerby, M. C. \& Ansell, L. L. - Catal. Today, 62, p.77 (2000).

17. Masson, J. F.; Polomark, G. M.; Bundalo-Perc, S. \& Collins, P. Therm. Acta., 440, p.132 (2006).

18. King L. F. \& Noel, F. - Polymer. Eng. Sci., 12, p.112 (1972).

19. ASTM - "ASTM Standard D 570 - 98 - Standard test method for water absorption of plastics", American Society for Testing and Materials, West Conshohocken, PA (1998). 
20. Torres, A. A. U. - "Envelhecimento físico-químico de tubulações de polietileno de alta densidade empregadas em redes de distribuição de derivados de petróleo", Dissertação de Mestrado, PUC-Rio (2007).

21. Snyder, R. G. - "Spectroscopic methods, infrared and raman spectra of polymers", in: Methods of experimental physics - Vol. 16: polymers. Part A: molecular structure and dynamics, Fava, R. A.; Marton, L. \& Marton, C. (ed.), Academic Press, New York, p.132-143 (1980).

22. Stuart, B. - "Infrared spectroscopy fundamentals and applications", John Wiley and Sons, New York (2004).

23. Bower, D. I. \& Maddams, W. F. - "The vibrational spectroscopy of polymers", Cambridge University Press, Cambridge (1989).
24. Predoi-Cross, A.; Lees, R. M.; Johns, J. W. C. - J. Mol. Spectrosc., 191, p.348 (1998).

25. McDonough, L. A.; Chikan, V.; Kim, Z. H.; Leone, S. R. \& Hinsberg, W. D. - J. Vac. Sci. Technol. B, 23, 344 (2005).

26. Maurin, M. B.; Dittert, L.W. \& Hussain, A. A. - Therm. Acta., 186, p. 97 (1991).

27. Ghazanfari, A.; Emami, S.; Tabil, L. G. \& Panigrahi, S. - Dry. Technol., 24, p.1631 (2006).

Enviado: 08/03/10

Reenviado: $17 / 05 / 10$

Aceito: $24 / 05 / 10$

DOI: $10.1590 / S 0104-14282011005000001$ 